\title{
Celiotomia exploratória em égua prenhe em terço final de gestação: relato de caso
}

Fernanda Fonseca", Priscila Aparecida dos Santos, Alfredo Saraceni Basilio, Leticia Ramalho Izzo, Gabriel Vinicius Rios Arantes, Wagner Aparecido de Oliveira Mota, Pedro Henrique Pinto, Verena Hildegard Gyárfas Wolf, Francisco Antônio de Toledo Mello Neto, Alex eduardo Alves Martins

*Autor correspondente

e-mail: fefa_fonseca@hotmail.com

\section{Resumo}

A síndrome cólica é a afecção mais prevalente de encaminhamento para hospitais veterinários, e a que apresenta maior morbidade e mortalidade entre os sistemas acometidos, podendo ocorrer aborto em $16 \%$ a $18 \%$ dos casos envolvendo éguas gestantes. As causas para tal condição podem estar associadas ao manejo alimentar dos equinos, juntamente com sua anatomia, predispondo ao aparecimento das alterações gastrointestinais. Égua da raça Mangalarga Machador, de 4 anos de idade, pesando $400 \mathrm{~kg}$, com 8 meses de gestação, alimentação à base de silagem de milho, foi encaminhada ao Hospital Veterinário Dr. Bernardo Aronovich - HVET FESB, em setembro de 2016, com queixa principal de desconforto abdominal. Na avaliação clínica o animal apresentou taquicardia, taquipnéia, hipomotilidade em todos os quadrantes e dor severa, mesmo sob o efeito de analgésicos. Na palpação retal, o útero apresentava-se dorsal, impossibilitando a continuidade da mesma. Após análise clínica, laboratorial (líquido peritoneal e lactato) e evolução do quadro, foi encaminhada para celiotomia exploratória, sendo observado encarceramento de íleo em forame epiplóico, sablose e torção em seguimento jejunal com comprometimento vascular de aproximadamente 1,5 m de comprimento. Em função da complexidade clínico-cirúrgica, o transoperatório se estendeu por 7 horas. As alças de intestino delgado apresentavam muito conteúdo líquido, sendo necessária enterotomia de jejuno, para melhorar a exposição, manipulação e diminuição de endotoxemia circulatória. Após avaliação criteriosa das alças, optou-se pela enteroanastomose do segmento comprometido. 0 tratamento pós-operatório consistiu na administração de Ceftiofur (4,4 mg/kg), Gentamicina (6,6 mg/kg), Flunixina Meglumine (1,1 mg/kg), Heparina (50 UI/kg), Ranitidina (2 mg/kg), Dimetilsulfóxido ( $1 / 2 \mathrm{ml} / \mathrm{kg}$ ), Morfina (0,1 mg/kg), Gastrozol Pasta (Dose $300 \mathrm{~kg}$ ), Óleo Mineral (20 ml) e fluidoterapia suporte. Após 48 horas pós-operatória houve estabilização clínica do animal, não apresentando refluxo e manutenção volêmica, optando-se pela diminuição na dose de Flunixina Meglumine para dose antitoxêmica $(0,25 \mathrm{mg} / \mathrm{kg})$. Em 
decorrência da melhora no quadro toxêmico, 72 h pós-operatório foi realizada uma ultrassonografia para verificar a vitalidade fetal. 0 paciente ficou internado durante 12 dias não demonstrando nenhuma alteração clínica, recebendo alta e parindo normalmente na data prevista. As afecções gastrointestinais mais comuns em éguas gestantes são as de intestino grosso, como compactações e torções, sendo incomuns ocorrências de afecções de intestino delgado. 0 tratamento preconizado em éguas gestantes inclui a redução e prevenção dos efeitos endotoxêmicos. evitando a ocorrência da hipóxia maternal, pois ambos os fatores são responsáveis pela alta taxa de morte embrionária e aborto em éguas gestantes com síndrome cólica.

Palavras-chave: Cólica. Prenhês. Celiotomia exploratória. 